\title{
Adsorption of Nickel in Aqueous Solution onto Natural Maghnite
}

\author{
Mohamed Amine Zenasni ${ }^{1,2,3, *}$, Said Benfarhi ${ }^{2}$, André Merlin ${ }^{3}$, Stéphane Molina ${ }^{3}$, Béatrice George ${ }^{3}$, \\ Bahia Meroufel ${ }^{1,3}$
}

${ }^{1}$ Institute of Sciences and Technology, Department of Sciences, Bechar University, Bechar, Algeria; ${ }^{2}$ Institute of Sciences, Department of Chemistry, Batna University, Batna, Algeria; ${ }^{3}$ Laboratory of Studies and Research on Material Wood (LERMAB), University of Lorraine, Nancy, France.

Email: *am.zenasni@gmail.com

Received December $4^{\text {th }}, 2012$; revised January $1^{\text {st }}, 2013$; accepted January $5^{\text {th }}, 2013$

\begin{abstract}
Maghnite clay obtained from Tlemcen, Algeria was investigated to remove heavy metal ion from wastewater. Thus, the present study includes the adsorption of $\mathrm{Ni}$ (II) in aqueous solution on maghnite clay through the process of adsorption under various conditions (with variable concentration of metal ion, temperature, $\mathrm{pH}$ and mixing time). Increasing $\mathrm{pH}$ favours the removal of metal ions till they are precipitated as the insoluble hydroxides. The uptake is rapid with maximum adsorption being observed within $10 \mathrm{~min}$ for $\mathrm{Ni}(\mathrm{II})$. In addition, the results obtained from adsorption isotherm indicated that these data can be better fitted with the Langmuir and Freundlich equations than the Dubinin-Radushkevich (D-R) equation.
\end{abstract}

Keywords: Natural Maghnite; Ni(II); Adsorption

\section{Introduction}

The increasing levels of toxic heavy metals or radionuclides, which have been discharged into the environment as industrial wastes, pose a serious threat to human health, living resources and ecological systems. Among the potentially contaminants, nickel is one of the most widespread pollutants in the environment. It is generally regarded that the wastewater containing nickel is mainly derived from industrial production processes including mining, electrolysis, electroplating, batteries dyes metallurgy, pesticides, etc. [1]. ${ }^{63} \mathrm{Ni}(\mathrm{II})\left(\mathrm{T}_{1 / 2}=96 \mathrm{a}\right)$, an important product of the neutron activation of the reactor materials, is present in liquid wastes released from pressurized water from the nuclear power reactors and is also widely used in research and medical applications. The presence of nickel in drinking water above the permissible limit of $0.02 \mathrm{mg} / \mathrm{L}$ (WHO drinking-water quality standards) can cause adverse health impacts such as anemia, diarrhea, encephalopathy, hepatitis and the dysfunction of central nervous system. For ecosystem stability and public health sake, it is of great importance to remove nickel from wastewaters. Among most methods of wastewater management, sorption technique has been widely used for the treatment of wastewater and

\footnotetext{
"Corresponding author.
}

retention of nuclear waste due to its simplicity of design, high sorption efficiency and low cost. In Sweden, the Svensk Karnbranslehantering AB (SKB, the Swedish Nuclear Fuel and Waste Management Co.) presents an $\mathrm{R} \& \mathrm{D}$ program every three years to manage spent nuclear fuel and other radioactive waste [2]. The studies on the sorption of radionuclides have been extensively conducted. Many $R \& D$ programs and various results have been reported [3-8]. For the long-term performance assessment of nuclear waste, it is of great significance to obtain in-depth understanding on the sorption mechanism of radionuclides at solid/water interfaces.

Adsorption reactions of toxic elements onto clay minerals are critical geochemical processes that affect their bioavailability and movement in both soils and sediments. Bentonite (especially maghnite), an expanding 2:1 phyllosilicate clay mineral, is a common component widely distributed in warm and semi-arid temperate regions [9]. Because of its high cation exchange capacity (CEC), swelling properties and large surface area, bentonite is also routinely used as an effective barrier in nuclear waste or hazardous chemical landfills to prevent contamination of groundwater and sub-soils [10-13].

Maghnite is a smectitic clay with a permanent negative structural charge, $\equiv \mathrm{X}^{-}$, generated largely in the octahedral sheet through isomorphous substitution of $\mathrm{Al}^{3+}$ with 
$\mathrm{Mg}^{2+}$, and a smaller variable charge that can be either positive, $\equiv \mathrm{S}_{-} \mathrm{OH}_{2}{ }^{+}$, or negative, $\equiv \mathrm{S}-\mathrm{O}^{-}$, generated by proton adsorption/desorption reactions at the edges of the mineral. The CEC of bentonite range from 0.70 to 1.30 mole $\cdot \mathrm{kg}^{-1}$, with up to $80 \%$ of the exchange capacity derived from the structural charge and the rest from the negative variable charges on the edges of the mineral [14]. The permanent structural charge derived from isomorphous substitution or non-ideal octahedral occupancy can be calculated from a chemical analysis of the clay.

The present study investigates the removal of Ni (II) from aqueous solution using maghnite. The effect of initial heavy metal concentrations was studied and the relationship between $\mathrm{pH}$ and removal efficiency was analysed. Experimental results were analysed using the Langmuir, Freundlich and Dubinin-Radushkevich isotherms. The presence of functional groups in the maghnite that may have a role in the sorption process was confirmed by FTIR. The maghnite sample was characterized by scanning electron microscopy (SEM), transmission electron microscopy (TEM) and TG-DTA.

\section{Materials and Methods}

\subsection{Materials}

\subsubsection{Adsorbent and Characterization}

The maghnite used in this work came from a quarry located in Maghnia (North West of Algeria) and was supplied by company "ENOF" (an Algerian manufacture specialized in the production of nonferric products and useful substances). The different chemical elements of the native maghnite were transformed into oxides and analysed by X-ray fluorescence (experiment carried out at ENOF). This maghnite form is stable suspensions in water and had flat platelets or needle-like structures. Granulometry of the crude maghnite have been prepared in the Civil Engineering Department of Tlemcen University (EDTU) in Algeria using a sedimentation technique with a $0.1 \%$ solution of sodium hexametaphosphate; $95 \%$ of the particles were found to have a diameter of less than $80 \mu \mathrm{m}$. The cation exchange capacity was measured to be $101.25 \mathrm{meq} / 100 \mathrm{~g}$ of clay, and the surface area was $27 \mathrm{~m}^{2} / \mathrm{g}$, with an average pore size of $7 \mathrm{~nm}$.

The Fourier transform infrared (FT-IR) spectra using $\mathrm{KBr}$ pressed disk technique were conducted by Perkin Elmer Spectrum 2000 Infrared spectrometer. Natural maghnite and $\mathrm{KBr}$ were weighted and then were ground in an agate mortar for $10 \mathrm{~min}$ prior to pellet making. The spectrums were collected for each measurement over the spectral range of $400-4000 \mathrm{~cm}^{-1}$.

TG-DTA thermograms were plotted using the multimodule 92 - 10 Setaram analyser operating from room temperature up to $1000^{\circ} \mathrm{C}$ in a $\mathrm{Al}_{2} \mathrm{O}_{3}$ crucible, at $10^{\circ} \mathrm{C} / \mathrm{mn}$ heating rate.

Nanomorphology was characterized by scanning electron microscopy (SEM) and transmission electron microscopy (TEM). The SEM study was carried out using Hitachi S-4800 equipped with energy dispersive spectrometry for chemical analysis (EDS) and operating at 15 $\mathrm{kV}$ acceleration voltage. TEM study was performed with a Philips CM10 microscope operating at $100 \mathrm{kV}$.

\subsubsection{Adsorbate $\left(\mathrm{Ni}^{2+}\right)$ and Other Chemicals}

All chemicals used were of analytical grade. Stock standard solution of $\mathrm{Ni}^{2+}$ has been prepared by dissolving the appropriate amount of $\mathrm{Ni}\left(\mathrm{NO}_{3}\right) \cdot 6 \mathrm{H}_{2} \mathrm{O}$ in deionized water, acidified with small amount of nitric acid. This stock solution was then diluted to specified concentrations. The $\mathrm{pH}$ of the system was adjusted using reagent grade $\mathrm{NaOH}$ and $\mathrm{HCl}$ respectively. All plastic sample bottles and glassware were cleaned, then rinsed with deionized water and dried at $60^{\circ} \mathrm{C}$ in a temperature controlled oven. All measurements were conducted at a room temperature of $20^{\circ} \mathrm{C}$. The concentration of $\mathrm{Ni}^{2+}$ was measured using Varian 100 Atomic Absorption Spectrophotometer (AAS). The $\mathrm{pH}$ of all solution was measured by a TitraLab Instrument TIM 800 Model $\mathrm{pH}$ meter.

\subsection{Adsorption Experiments}

\subsubsection{Adsorption Procedure}

Adsorption measurements were determined by batch experiments. For this purpose, $0.2 \mathrm{~g}$ of maghnite and 40 $\mathrm{mL}$ of aqueous $\mathrm{Ni}^{2+}$ solutions at specified concentration were put on a shaker using a thermostated shaker bath GFL-1083 Model at $20^{\circ} \mathrm{C}$ for a given time. The suspensions were then centrifuged by Eppendorf 5702 Model digital and these solutions were analyzed using flame atomic absorption spectrophotometer with air-acetylene flame. The $\mathrm{pH}$ of the solutions was initially adjusted by addition of small amount of either $0.1 \mathrm{M} \mathrm{HCl}$ or $0.1 \mathrm{M}$ $\mathrm{NaOH}$ solutions. The experiments were carried out by varying concentrations of initial $\mathrm{Ni}^{2+}$ solution, contact time, temperature and $\mathrm{pH}$ of initial suspension. The $\mathrm{Ni}^{2+}$ concentration retained in the adsorbent phase, $\mathrm{q}_{\mathrm{e}}(\mathrm{mg} / \mathrm{g})$ was calculated according to following relation [15]:

$$
q_{e}=\frac{\left(C_{0}-C_{e}\right) V}{m}
$$

where $C_{0}(\mathrm{mg} / \mathrm{L})$ and $C_{e}(\mathrm{mg} / \mathrm{L})$ are the concentration in the solution at time $\mathrm{t}=0$ and at time $\mathrm{t}$ respectively, $V$ is the volume of solution ( $\mathrm{L}$ ) and $\mathrm{m}$ is the amount of adsorbent $(\mathrm{g})$ added.

Adsorption percentage (\%) was derived from the difference of the initial concentration $\left(C_{0}, \mathrm{~mol} / \mathrm{L}\right)$ and the final one $\left(C_{e}, \mathrm{~mol} / \mathrm{L}\right)$ (Equation (2)): 


$$
\text { Sorption } \%=\frac{C_{0}-C_{e}}{C_{0}} \times 100 \%
$$

\subsubsection{Effect of $\mathbf{P H}$}

In this study the sorbent $(0.2 \mathrm{~g})$ and $20 \mathrm{~mL}$ of $100 \mathrm{ppm}$ $(\mathrm{mg} / \mathrm{L}) \mathrm{Ni}^{2+}$ solution were mixed in plastic bottle. The $\mathrm{pH}$ of the mixture was adjusted either by $0.1 \mathrm{M} \mathrm{HCl}$ or $0.1 \mathrm{M} \mathrm{NaOH}$ solution until the initial $\mathrm{pH}$ was close to the target value ranged from 2.5 to 7.5 . The whole mixture was taken in a series of $50 \mathrm{~mL}$ plastic bottles and put on a thermostated shaker bath and at $20^{\circ} \mathrm{C}$ for a period of 10 min. Speed was such that it maintains the contents completely mixed and the adsorbents were suspended throughout the plastic bottle. The samples were then collected in different time intervals throughout equilibrium time period and centrifuged each time. The left out concentrations in the solution was analyzed using flame atomic absorption spectrophotometer. The quantity of adsorbed metal ion on maghnite was calculated as the difference between initial concentration and concentration at any time, $t$ as per (Equation (1)). Each experiment was repeated in twice to check the reproducibility. Measurements are, in general, reproducible within $\pm 10 \%$.

\subsubsection{Effect of Temperature}

The batch adsorption experiments were carried out with $20 \mathrm{~mL} \mathrm{Ni(II)} \mathrm{metal} \mathrm{ion} \mathrm{solution} \mathrm{of} 100 \mathrm{ppm}$ at 20, 30, 40, 50 and $60^{\circ} \mathrm{C}$ separately by contacting with $0.2 \mathrm{~g}$ of adsorbent using thermostated shaker bath for $10 \mathrm{~min}$. The solution $\mathrm{pH}$ was 7.5 .

\subsubsection{Equilibrium Isotherm Experiments}

For isotherm studies, a series of $50 \mathrm{~mL}$ plastic bottles containing $20 \mathrm{~mL}$ of $\mathrm{Ni}^{2+}$ metal ions solutions of known concentrations, varying from 10 to $500 \mathrm{mg} / \mathrm{L}$ were prepared. Identical amounts $(0.2 \mathrm{~g})$ of maghnite were added to the each bottle and the resulting suspensions were agitated on a thermostated shaker bath at $20^{\circ} \mathrm{C}$ for $10 \mathrm{~min}$ at a constant $\mathrm{pH}$ of 7.5. After equilibrium time, the suspensions were then centrifuged and the solutions were analyzed using flame atomic absorption spectrophotometer with air-acetylene flame.

\section{Results and Discussions}

\subsection{Characterization of Adsorbent}

Chemical analysis data of the natural maghnite are presented in Table 1.
These results confirm that the maghnite used consists essentially of montmorillonite, since the ratio $\mathrm{SiO}_{2} / \mathrm{Al}_{2} \mathrm{O}_{3}$ is equal to 3.77 and thus belongs to the family of the phyllosilicates.

FT-IR studies of these adsorbents help the identification of various forms of the minerals that are present in the clay. Infrared spectra of the charge maghnite, illustrated in Figure 1, show the presence of absorption bands of clay phase and absorption characteristic bands of impurities.

A strong band at $3623.90 \mathrm{~cm}^{-1}$ and $3464.43 \mathrm{~cm}^{-1}$ indicates the possibility of the hydroxyl linkage. However, a broad band at $3464.43 \mathrm{~cm}^{-1}$ and a band at $1631.34 \mathrm{~cm}^{-1}$ in the spectrum of clay suggest the possibility of water of hydration in the adsorbent. The bands due to free (or weakly hydrogen-bonded water molecule to the surface oxygen of tetrahedral sheet) water molecules, waterwater hydrogen bond $\left(\mathrm{M}^{\mathrm{n}+}-\mathrm{O}-\mathrm{H}-\mathrm{O}-\mathrm{H}-\right)$ and water bending modes are observed near 3623.90, 3464.43 and $1631.34 \mathrm{~cm}^{-1}$, respectively. The strong band near $1037.10 \mathrm{~cm}^{-1}$ is due to $\mathrm{Si}-\mathrm{O}-\mathrm{Si}$ stretching vibration in tetrahedral sheets, which corresponds to the characteristic band of montmorillonite [16]. The coupled vibrations are appreciable due to the availability of various constituents. In the IR studies of maghnite, the Si-O stretching vibrations were observed at $697.86 \mathrm{~cm}^{-1}, 524.86 \mathrm{~cm}^{-1}$ and $469.95 \mathrm{~cm}^{-1}$ showing the presence of quartz. The appearance of $v(\mathrm{Si}-\mathrm{O}-\mathrm{Si})$ and $\delta(\mathrm{Si}-\mathrm{O})$ bands also support the presence of quartz [17]. The vibrations observed at $912.24 \mathrm{~cm}^{-1}$ indicate the possibility of the presence of hematite [18].

Result from thermal analysis is reported in Figure 2. The TG curve of the natural maghnite shows three main steps of weight loss. In the first step $\left(\mathrm{T}<200^{\circ} \mathrm{C}\right)$ a weight loss (about 18.50\%) corresponding to both adsorbed and interlayer water loss takes place. After this step, the TG curve shows a slight gradual decrease (about $2.10 \%$ ) in the range $200^{\circ} \mathrm{C}-580^{\circ} \mathrm{C}$, which is attributed to the water loss of maghnite. Finally, a third main loss occurs at temperatures in the range $580^{\circ} \mathrm{C}-900^{\circ} \mathrm{C}$, where the TG curve displays a step weight loss (about $4.11 \%$ ) related to the release of structural $\mathrm{OH}$ of natural maghnite. The dehydroxylation temperature of about $650^{\circ} \mathrm{C}$ (see Figure 2) is in agreement with the classical range of dehydroxylation temperature $\left(600^{\circ} \mathrm{C}-700^{\circ} \mathrm{C}\right)$ observed by various authors for cis vacant montmorillonites [19].

SEM micrograph of the untreated maghnite sample suggests a very cohesive material (Figure 3 ). The micro-

Table 1. Chemical composition of the maghnite.

\begin{tabular}{cccccccccc}
\hline Species & $\mathrm{SiO}_{2}$ & $\mathrm{Al}_{2} \mathrm{O}_{3}$ & $\mathrm{Fe}_{2} \mathrm{O}_{3}$ & $\mathrm{CaO}$ & $\mathrm{MgO}$ & $\mathrm{Na}_{2} \mathrm{O}$ & $\mathrm{K}_{2} \mathrm{O}$ & $\mathrm{TiO}_{2}$ & ${\mathrm{~L} . \mathrm{O} . \mathrm{I}^{*}}^{2}$ \\
\hline$\%(w / w)$ & 65.20 & 17.25 & 2.10 & 1.20 & 3.10 & 2.15 & 0.60 & 0.20 & 8.20 \\
\hline
\end{tabular}

* L.O.I: Loss on ignition. 


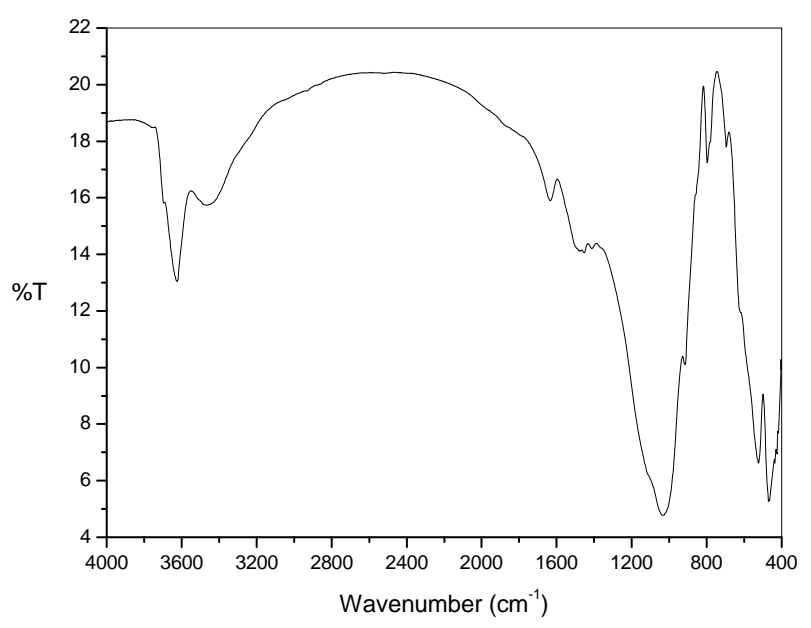

Figure 1. Infrared (IR) spectra of natural maghnite.

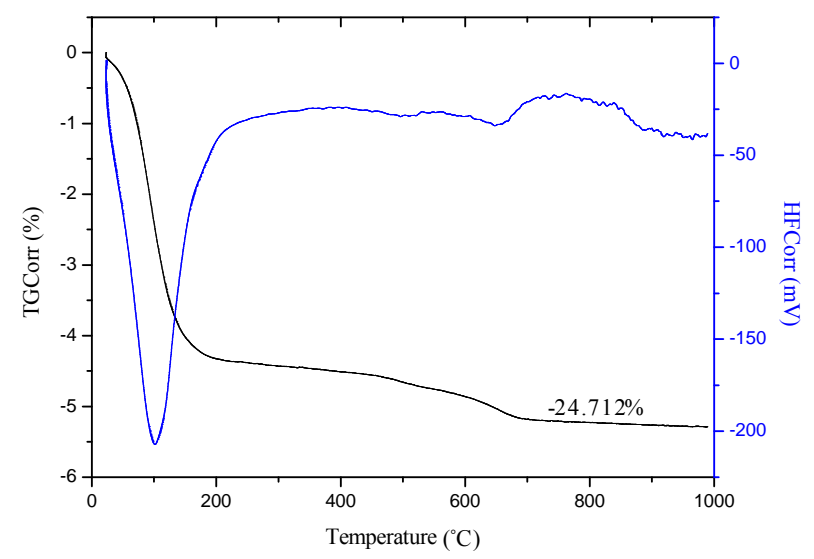

Figure 2. TG-DTA analyse of natural maghnite.

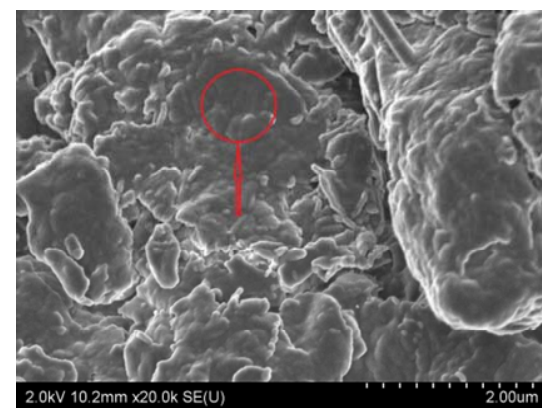

Figure 3. SEM image of maghnite sample.

graph confirms that the material is forming micron-size agglomerates. A higher magnification micrograph of the same structure shows that the micro-size particles are composed of individual platelets, which conglomerate into larger size particles.

The obtained chemical analysis by energy dispersive spectroscopy (Figure 4) shows the presence of framework $\mathrm{Al}$ and $\mathrm{Si}$ elements. The molar $\mathrm{Si} / \mathrm{Al}$ ratio for used maghnite is about 2.78. The presence also of the $\mathrm{Na}, \mathrm{K}$ and $\mathrm{Mg}$ elements in the structure of maghnite.

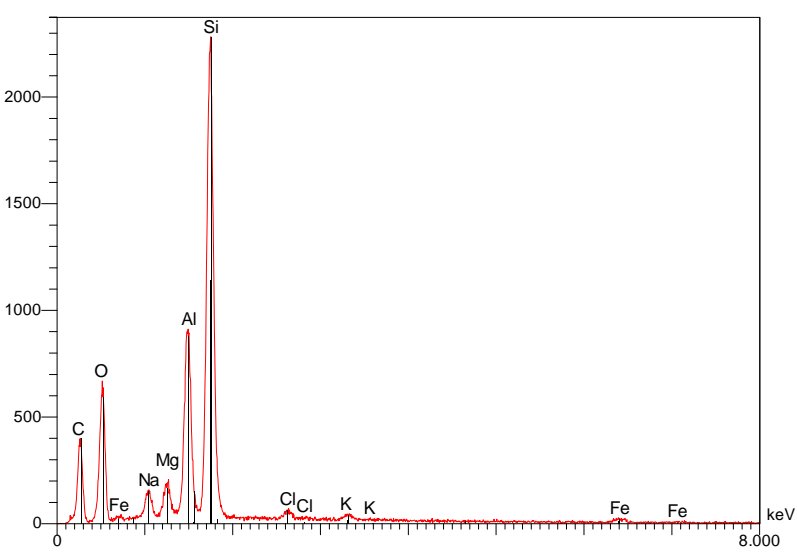

Figure 4. SEM-EDS spectra of maghnite sample.

The TEM micrographs at low magnification showed (Figure 5) a higher tendency of the maghnite to aggregate.

\subsection{Effect of Initial Concentration of Ni(II)}

Effect of initial concentration of $\mathrm{Ni}$ (II) on adsorption capacity of maghnite was investigated by varying initial concentration of $\mathrm{Ni}(\mathrm{II})$ from 10 to $500 \mathrm{mg} / \mathrm{L}$. For this study, $\mathrm{pH}$, temperature, adsorbent dosage and contact time have been fixed as $20^{\circ} \mathrm{C}, 0.2 \mathrm{~g} / 20 \mathrm{~mL}$ and $10 \mathrm{~min}$. The results are presented in Figure 6. An increase of $\mathrm{Ni}$ (II) concentration accelerates the diffusion of $\mathrm{Ni}(\mathrm{II})$ ions from solution to the adsorbent surface due to the increase in driving force of concentration gradient. Hence, the amount of adsorbed $\mathrm{Ni}$ (II) at equilibrium increased from 0.98 to $18.5 \mathrm{mg} / \mathrm{g}$ as the $\mathrm{Ni}$ (II) concentration is increased from 10 to $500 \mathrm{mg} / \mathrm{L}$.

\subsection{Effect of pH}

Effect of initial $\mathrm{pH}$ on the adsorption capacity of maghnite for $\mathrm{Ni}$ (II) was studied by varying solution $\mathrm{pH}$ from 2.5 to 7.5 at the adsorbent dosage of $0.2 \mathrm{~g} / 20 \mathrm{~mL}$ using an initial concentration of $\mathrm{Ni}(\mathrm{II})$ as $100 \mathrm{mg} / \mathrm{L}$. The $\mathrm{pH}$ range of 2.5 - 7.5 was chosen, as the precipitation of $\mathrm{Ni}(\mathrm{II})$ is found to occur at $\mathrm{pH} \geq 8$ [20]. Variation of adsorption capacity of maghnite for $\mathrm{Ni}(\mathrm{II})$ ions with $\mathrm{pH}$ is shown in Figure 7. It is evident that the adsorption of $\mathrm{Ni}$ (II) ions on maghnite is strongly dependant on the $\mathrm{pH}$ of the solution. The adsorption of $\mathrm{Ni}$ (II) ions increases steadily with increase in initial $\mathrm{pH}$ from 2.5 to 7.5 and the maximum adsorption capacity of $9.96 \mathrm{mg} / \mathrm{g}$ is observed at $\mathrm{pH} 7.5$.

\subsection{Effects of Interaction Time and Kinetics of Adsorption}

The adsorption of $\mathrm{Ni}(\mathrm{II})$ on maghnite as a function of contact time at pH $7.5 \pm 0.1$ is shown in Figure 8.

The Ni(II) interacted with the maghnite rapidly and 


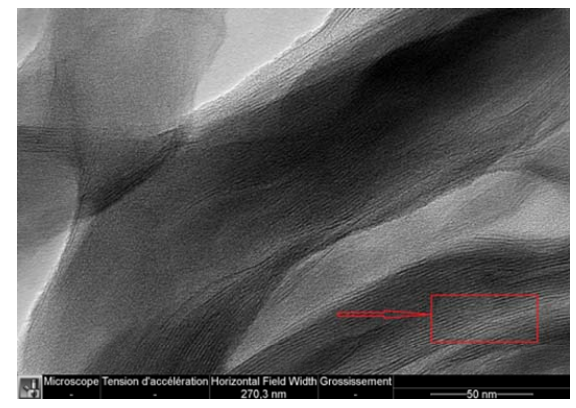

Figure 5. TEM micrograph of the maghnite.

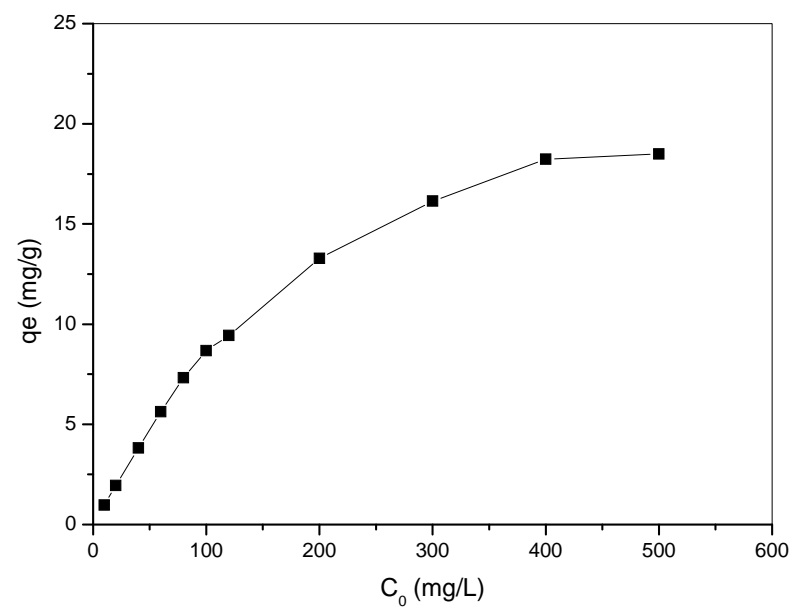

Figure 6. Effect of initial concentration of Ni(II) on adsorption capacity of maghnite.

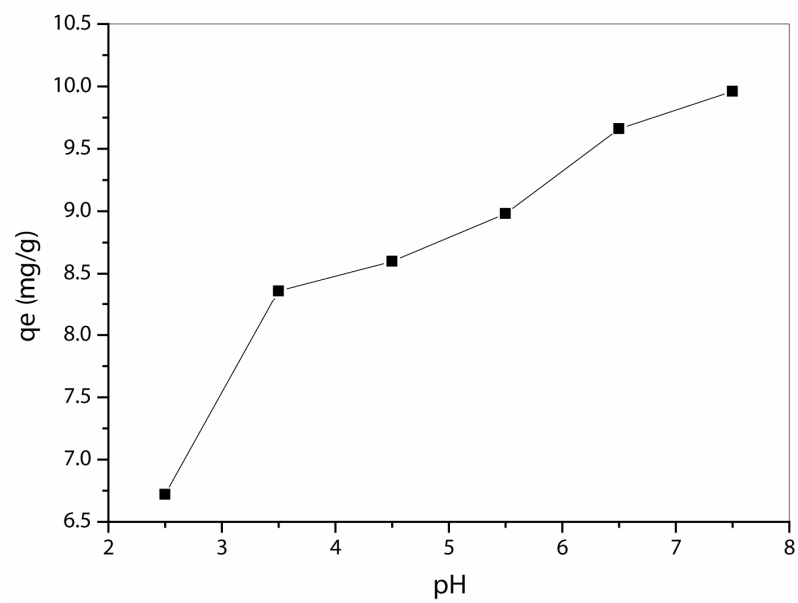

Figure 7. Effect of pH on adsorption capacity of maghnite for $\mathrm{Ni}(\mathrm{II})$.

within $6 \mathrm{~min}$, the maximum uptake was observed (Figure 8). Afterwards, the interactions slowed down and approached equilibrium in nearly $10 \mathrm{~min}$ under the given set of experimental conditions.

Attainment of equilibrium is influenced by several factors including the nature of the adsorbent and the adsorbate, and the interactions between them.

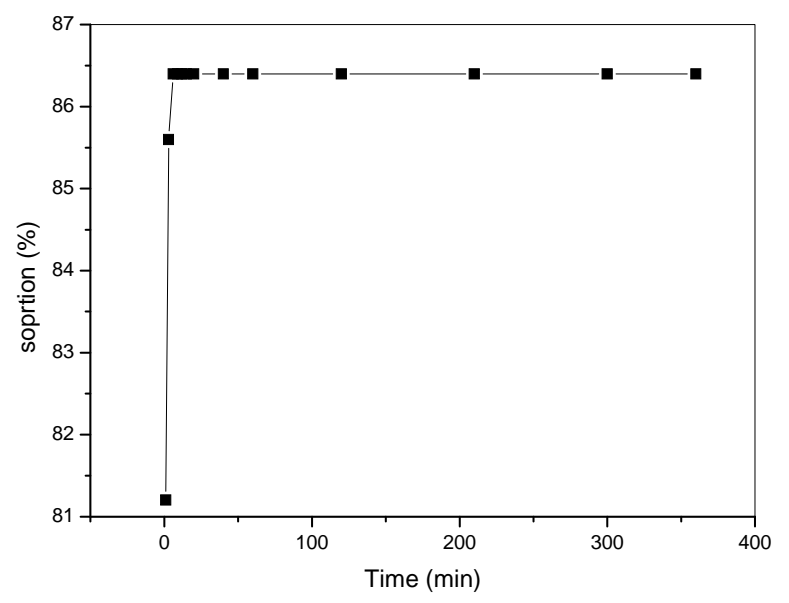

Figure 8. Effect of contact time on the adsorption of $\mathrm{Ni}(\mathrm{II})$ to maghnite, $\mathrm{pH}=7.5 \pm 0.1, \mathrm{~T}=293 \mathrm{~K}$, clay $10 \mathrm{~g} / \mathrm{L}$, C[Ni(II) $]$ initial $=100 \mathrm{mg} / \mathrm{L}$.

Initially, the rate of adsorption on the bare surface was very high, but as the sites got covered with the Ni(II), the rate decreased. The rate now becomes predominantly dependent on the rate at which metal ions are transported from the bulk liquid phase to the adsorbent-adsorbate interface. The kinetics of the interactions is thus likely to be dependent on different rate processes as the interaction time increases [21].

In this study, $86 \%$ of $\mathrm{Ni}(\mathrm{II})$, was adsorbed on the maghnite clay when the equilibrium was reached at 10 min. On the basis of this result, it can be observed that natural maghnite clay can be used to remove this metal ion.

The fast adsorption of $\mathrm{Ni}(\mathrm{II})$ on maghnite suggested that the uptake of $\mathrm{Ni}$ (II) from solution to maghnite was mainly dominated by chemical adsorption rather than physical adsorption [22,23].

To analyze the kinetic adsorption of Ni(II) on maghnite, a pseudo-second-order rate equation was used to simulate the kinetic adsorption (Equation (3)) [24]:

$$
\frac{t}{q_{t}}=\frac{1}{2 K^{\prime} q_{e}^{2}}+\frac{1}{q_{e}} t
$$

where $q_{t}(\mathrm{mg} / \mathrm{g})$ is the amount of $\mathrm{Ni}(\mathrm{II})$ adsorbed on maghnite at time $t(\mathrm{~min}), q_{e}(\mathrm{mg} / \mathrm{g})$ is the equilibrium adsorption capacity and $K^{\prime}(\mathrm{g} /(\mathrm{mg} \cdot \mathrm{min}))$ is the pseudosecond-order rate constant of adsorption. The values of $K^{\prime}$ and $q_{e}$ calculated from the intercept and slope of equation are $5.23 \mathrm{~g} /(\mathrm{mg} \cdot \mathrm{min})$ and $8.64 \mathrm{mg} / \mathrm{g}$, respectively. The correlation coefficient of the pseudo-secondorder rate equation for the linear plot is 1.00 (see Figure 9), which suggests that the kinetic adsorption can be described by the pseudo-second-order rate equation.

\subsection{Construction of Isotherms and Model Fitting}

Sorption isotherms were constructed by plotting the 


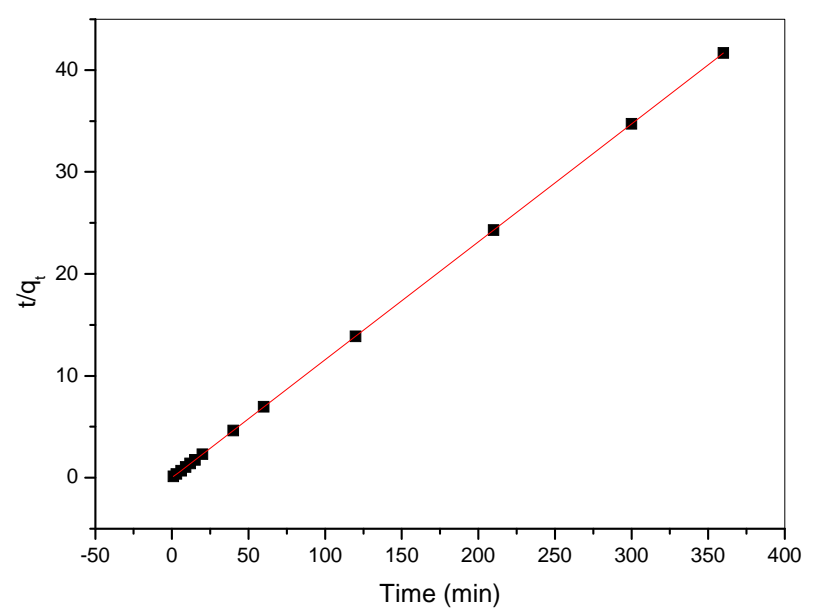

Figure 9. Lagergren pseudo second-order plots for Ni (II) adsorbed on maghnite at $293 \mathrm{~K}, \mathrm{pH}$ (7.5).

amount of metal sorbed $(\mathrm{mg} / \mathrm{g})$ against the equilibrium concentration of metal in solution $(\mathrm{mg} / \mathrm{L})$.

Three models have been adopted in this paper, namely: Langmuir, Freundlich and Dubinin-Radushkevich (D-R) equilibrium isotherm models. The Langmuir and Freundlich isotherms are used most commonly to describe the adsorption characteristics of metal ions in water and wastewater treatment [25].

\subsubsection{Langmuir Isotherm}

The data conform the linear form of Langmuir model (Equation (4)) [26] expressed below:

$$
\frac{C_{e}}{q_{e}}=\frac{C_{e}}{q_{m}}+\frac{1}{K_{L} q_{m}}
$$

where $C_{\mathrm{e}}$ is equilibrium concentration of $\mathrm{Ni}(\mathrm{II})(\mathrm{mg} / \mathrm{L})$ and $q_{\mathrm{e}}$ is the amount of the $\mathrm{Ni}^{2+}$ adsorbed (mg) by per unit of maghnite $(\mathrm{g}) . q_{\mathrm{m}}$ and $K_{\mathrm{L}}$ are the Langmuir constants related to the adsorption capacity $(\mathrm{mg} / \mathrm{g})$ and the equilibrium constant $(\mathrm{L} / \mathrm{g})$, respectively. The Langmuir monolayer adsorption capacity $\left(q_{\mathrm{m}}\right)$ gives the amount of the metal required to occupy all the available sites per unit mass of the sample (see Figure 10). The Langmuir monolayer adsorption capacities of maghnite was estimated as $18.95 \mathrm{mg} / \mathrm{g}$, (Table 2). The value of maximum adsorption capacity $\left(q_{\mathrm{m}}\right)$ calculated from the Langmuir isotherm in this study is much higher than that of those reported in the literature. For example, Langmuir adsorption capacity for $\mathrm{Ni}(\mathrm{II})$ adsorption on Oxidized CNTs and As-produced CNTs has been shown to be 9.26 and $18.08 \mathrm{mg} / \mathrm{g}$, respectively, by Kandah and Meunier [27].

\subsubsection{Freundlich Isotherm}

The adsorption equilibrium data was also applied to the Freundlich model (Equation (5)) [28] given:

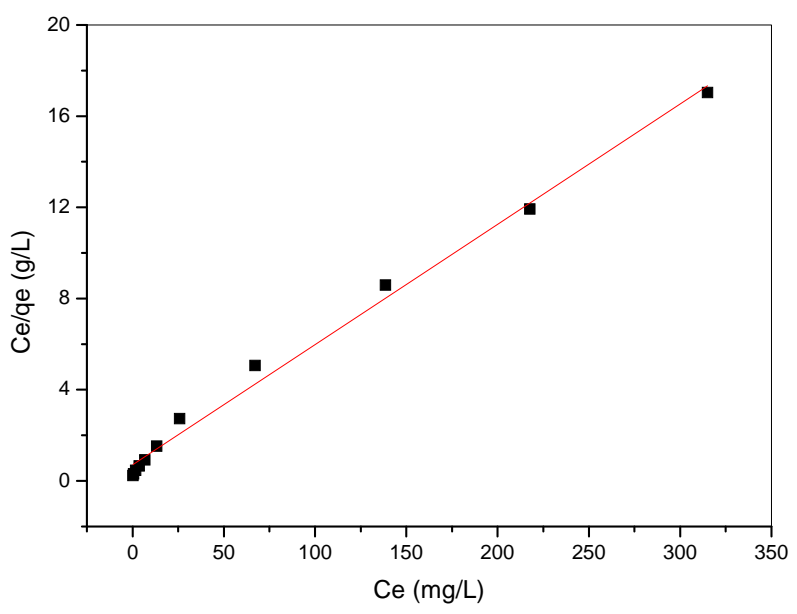

Figure 10. Langmuir isotherm plot for adsorption of $\mathrm{Ni}^{2+}$ on the maghnite. $T=293 \mathrm{~K}$, initial $\mathrm{pH} 7.5, m / V=10 \mathrm{~g} / \mathrm{L}$.

$$
\log q_{e}=\log K_{f}+\left(\frac{1}{n}\right) \log C_{e}
$$

where $K_{\mathrm{f}}$ and $n$ are Freundlich constants related to adsorption capacity and adsorption intensity, respectively. Freundlich parameters $\left(K_{\mathrm{f}}\right.$ and $\left.n\right)$ indicate whether the nature of adsorption is either favorable or unfavorable. The intercept is an indicator of adsorption capacity and the slope is an indicator of adsorption intensity. A relatively slight slope $n \square \quad 1$ indicates that adsorption intensity is good (or favorable) over the entire range of concentrations studied, while a steep slope $(n>1)$ means that adsorption intensity is good (or favorable) at high concentrations but much less at lower concentrations [29]. A high value of the intercept, $K_{\mathrm{f}}$, is indicative of a high adsorption capacity. In the adsorption system, $n$ value is 2.63 which indicates that adsorption intensity is good (or favorable) over the entire range of concentrations studied. The $K_{\mathrm{f}}$ value of the Freundlich equation (Table 2) also indicates that maghnite has a very high adsorption capacity for copper ions in aqueous solutions (see Figure 11).

\subsubsection{Dubinin-Radushkevich (D-R)}

The equilibrium data were also applied to the DubininRadushkevich (D-R) isotherm model to determine if adsorption occurred by physical or chemical processes. The linearized form of the D-R isotherm [30] is as follows (Equation (6)):

$$
\ln q_{e}=\ln q_{m}-\beta \varepsilon^{2}
$$

where $\beta$ is the activity coefficient related to mean adsorption energy $\left(\mathrm{mol}^{2} / \mathrm{J}^{2}\right)$ and $\varepsilon$ is the Polanyi potential (Equation (7)):

$$
\varepsilon=R \operatorname{Tln}\left(1+\frac{1}{C_{e}}\right)
$$

The D-R isotherm is applied to the data obtained from 
Table 2. Langmuir, Freundlich and $\mathrm{D}-\mathrm{R}$ isotherm parameters for the adsorption of $\mathrm{Ni}^{2+}$ onto maghnite sample.

\begin{tabular}{ccccccccccc}
\hline Sample & \multicolumn{2}{c}{ Langmuir isotherm constants } & \multicolumn{2}{c}{ Freundlich isotherm constants } & \multicolumn{3}{c}{ D-R isotherm constants } \\
\hline Maghnite & $q_{\mathrm{m}}(\mathrm{mg} / \mathrm{g})$ & $K_{\mathrm{L}}(\mathrm{L} / \mathrm{g})$ & $R^{2}$ & $\mathrm{n}$ & $K_{\mathrm{f}}$ & $R^{2}$ & $q_{\mathrm{m}}(\mathrm{mg} / \mathrm{g})$ & $E(\mathrm{~kJ} / \mathrm{mol})$ & $R^{2}$ \\
\hline & 18.95 & 0.07 & 0.992 & 2.63 & 2.64 & 0.940 & 9.71 & 1.83 & 0.664 \\
\hline
\end{tabular}

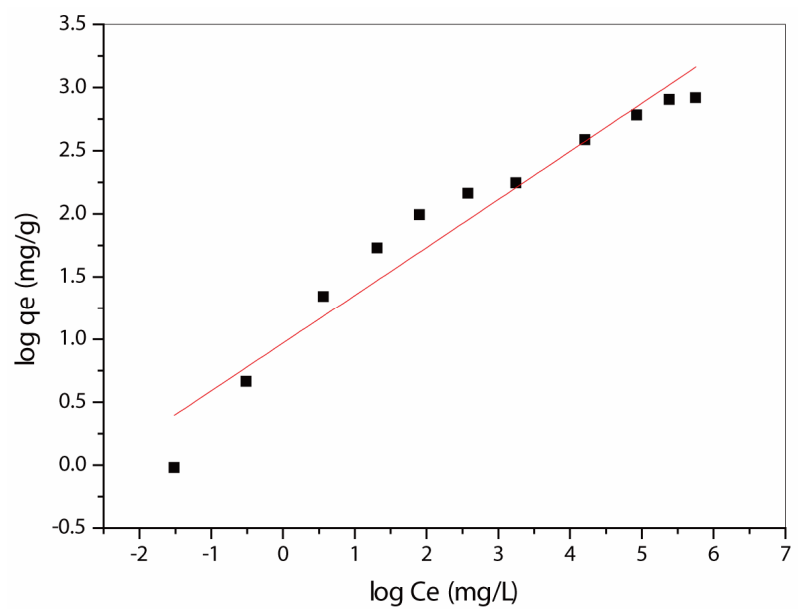

Figure 11. Freundlich isotherm plot for adsorption of $\mathrm{Ni}^{2+}$ on the maghnite. $T=293 \mathrm{~K}$, initial $\mathrm{pH} 7.5, \mathrm{~m} / \mathrm{V}=10 \mathrm{~g} / \mathrm{L}$.

the empirical studies. A plot of $\ln q_{\mathrm{e}}$ against $\varepsilon^{2}$ is given in Figure 12. D-R isotherm constants, $q_{\mathrm{m}}$, for maghnite was found to be $9.71 \mathrm{mg} / \mathrm{g}$ (Table 2).

The difference of $q_{\mathrm{m}}$ derived from the Langmuir and $\mathrm{D}-\mathrm{R}$ models is large. The difference may be attributed to the different definition of $q_{\mathrm{m}}$ in the two models. In Langmuir model, $q_{\mathrm{m}}$ represents the maximum adsorption of metal ions at monolayer coverage, whereas it represents the maximum adsorption of metal ions at the total specific micropore volume of the adsorbent in D-R model. Thereby, the value of $q_{\mathrm{m}}$ derived from Langmuir model is higher than that derived from D-R model. The differences are also reported in previous studies [30]. The mean adsorption energy, $E(\mathrm{~kJ} / \mathrm{mol})$ is as follows (Equation (8)):

$$
E=\frac{1}{\sqrt{-2 \beta}}
$$

This adsorption potential is independent of the temperature, but it varies depending on the nature of adsorbent and adsorbate. The magnitude of $E$ is used for estimating the type of adsorption mechanism. If the $E$ value is between 8 and $16 \mathrm{~kJ} / \mathrm{mol}$, the adsorption process follows by chemical adsorption and if $E<8 \mathrm{~kJ} / \mathrm{mol}$, the adsorption process is of a physical nature [30]. The calculated values of $E$ are $1.83 \mathrm{~kJ} / \mathrm{mol}$ for maghnite, and they are in the range of values for physical adsorption reactions. The similar results for the adsorption of $\mathrm{Ni}(\mathrm{II})$ was reported by earlier worker [29].

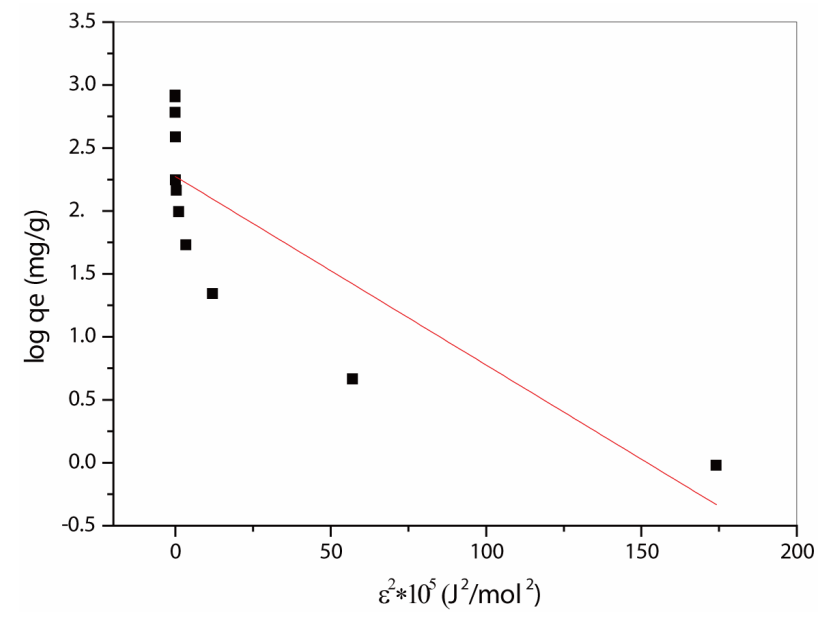

Figure 12. $\mathrm{D}-\mathrm{R}$ isotherm plot for adsorption of $\mathrm{Ni}^{2+}$ on the maghnite. $T=293 \mathrm{~K}$, initial $\mathrm{pH} 7.5, m=10 \mathrm{~g} / \mathrm{L}$ with $\mathrm{R}^{2}=$ 0.664: To demonstrate that this type of adsorption is bad compared the two other.

\subsection{Thermodynamic Studies}

Using the following equations, the thermodynamic parameters of the adsorption process were determined from the experimental data (Equations (9)-(11)):

$$
\begin{aligned}
& \ln K_{d}=\frac{\Delta S}{R}-\frac{\Delta H}{R T} \\
& \Delta G=\Delta H-T \Delta S \\
& K_{d}=\frac{q_{e}}{C_{e}}
\end{aligned}
$$

where $\mathrm{K}_{\mathrm{d}}$ is the distribution coefficient for the adsorption, $\Delta \mathrm{S}, \Delta \mathrm{H}$ and $\Delta \mathrm{G}$ are the changes of entropy, enthalpy and the Gibbs energy, $\mathrm{T}(\mathrm{K})$ is the temperature, $\mathrm{R}\left(\mathrm{J} \cdot \mathrm{mol}^{-1} \cdot \mathrm{K}^{-1}\right)$ is the gas constant. The enthalpy change $(\Delta \mathrm{H})$ is determined graphically by plotting $\ln \mathrm{K}_{\mathrm{d}}$ versus $1 / \mathrm{T}$ which gives a straight line (Figure 13) and the values of free energy $(\Delta \mathrm{G})$ and entropy $(\Delta \mathrm{S})$ computed numerically are presentedin Table 3.

Free energy values $(\Delta G)$ are very small and positive, and decreases with an increase of temperature. This indicates that better adsorption is obtained at higher temperature. The positive values of entropy may be due to some structural changes in the adsorbate and adsorbent during the adsorption process. The positive value of $\Delta \mathrm{H}$ indicate the endothermic behavior of the adsorption reaction of $\mathrm{Ni}(\mathrm{II})$ ions and suggest that a large amount of 
Table 3. Thermodynamic parameters for the adsorption of Ni(II) onto maghnite.

\begin{tabular}{|c|c|c|c|c|c|c|c|c|}
\hline \multirow[t]{2}{*}{ Sample } & \multirow{2}{*}{$\Delta H(\mathrm{~kJ} / \mathrm{mol})$} & \multirow{2}{*}{$\Delta S(\mathrm{~J} / \mathrm{mol} \mathrm{K})$} & \multicolumn{5}{|c|}{$\Delta G(\mathrm{~kJ} / \mathrm{mol})$} & \multirow{2}{*}{$R^{2}$} \\
\hline & & & $293 \mathrm{~K}$ & $303 \mathrm{~K}$ & $313 \mathrm{~K}$ & $323 \mathrm{~K}$ & $333 \mathrm{~K}$ & \\
\hline Maghnite & 6.81 & 17.87 & 1.57 & 1.39 & 1.22 & 1.04 & 0.86 & 0.895 \\
\hline
\end{tabular}

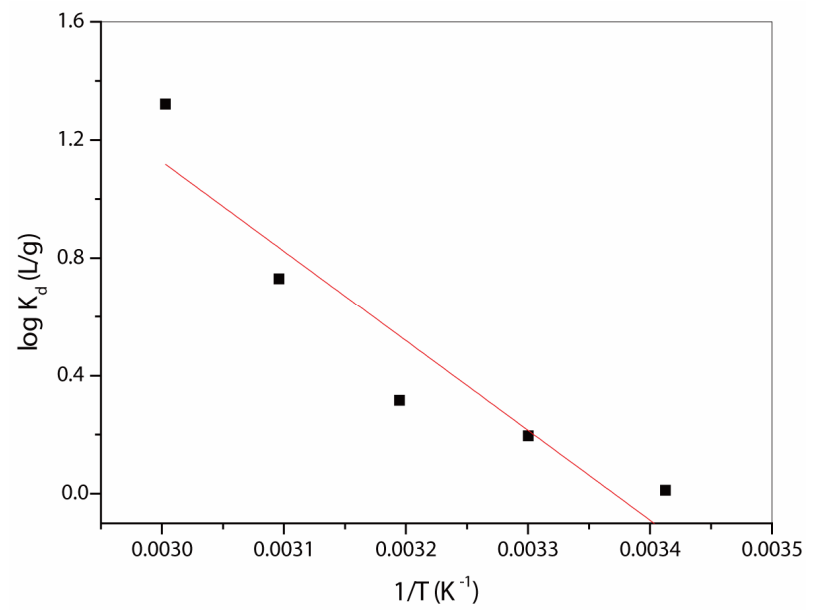

Figure 13. Plot of In Kd against $1 / \mathrm{T}$ for the adsorption of $\mathrm{Ni}$ (II) on maghnite, with $R^{2}=0.895$ : For this value of $R^{2}$ with four temperature value, the results are quite good compared with the literature.

heat is consumed to transfer the $\mathrm{Ni}$ (II) ions from aqueous into the solid phase. As was suggested by Nunes and Airoldi [31], the transition metal ions must give up a larger share of their hydration water before they could enter the smaller cavities. Such a release of water from the divalent cations would result in positive value of $\Delta S$. This mechanism of the adsorption of $\mathrm{Ni}(\mathrm{II})$ ions is also supported by the positive value of $\Delta \mathrm{S}$, which show that $\mathrm{Ni}$ (II) ions are less hydrated in the maghnite layers than in the aqueous solution. Also, the positive value of $\Delta \mathrm{S}$ indicates the increased disorder in the system with changes in the hydration of the adsorbing Ni(II) cations.

\section{Conclusion}

The present study investigated the performance of the maghnite in removing $\mathrm{Ni}$ (II) ions from aqueous solutions. The adsorption of Ni(II) depends upon the nature of the adsorbent surface and the species distribution of $\mathrm{Ni}$ (II) in solution, which mainly depends on the $\mathrm{pH}$ of the system. The experimental values were evaluated according to the Langmuir, Freundlich and D-R isotherms that are generally used to describe the adsorption processes. The plots have good linearity in both the cases (Freundlich plot, $R^{2}$ $=0.940$, Langmuir plot, $R^{2}=0.992$ ) at $293 \mathrm{~K}$. Conclusively, the maghnite is a feasible and effective adsorbent in removing $\mathrm{Ni}$ (II) ions from aqueous solution.

\section{Acknowledgements}

The authors gratefully acknowledge to the Dr Yves PILLET (Faculty of Sciences and Technology, group PGCM, University of Lorraine, Nancy, France) because of contribution to our study, and thankful for Joint Service Electronic Microscopy and Microanalysis at the University Henri Poincare of Nancy for MEB-EDS analysis.

\section{REFERENCES}

[1] H. Parab, S. Joshi, N. Shenoy, A. Lali, U. S. Sarma and M. Sudersanan, "Determination of Kinetic and Equilibrium of $\mathrm{Co}(\mathrm{II}), \mathrm{Cr}(\mathrm{III})$, and $\mathrm{Ni}(\mathrm{II})$ onto Coir Pith," Process Biochemistry, Vol. 41, No. 3, 2006, pp. 609-615. doi:10.1016/j.procbio.2005.08.006

[2] B. Rosborg and L. Werme, "The Swedish Nuclear Waste Program and the Long-Term Corrosion Behavior of Copper," Journal of Nuclear Materials, Vol. 379, No. 1-3, 2008, pp. 142-153. doi:10.1016/j.jnucmat.2008.06.025

[3] D. Cui and T. E. Eriksen, "Reduction of Tc(VII) and $\mathrm{Np}(\mathrm{V})$ in Solution by Ferrous Ion. A Laboratory Study of Homogeneous and Heterogeneous Redox Processes," SKB Technical Report, 1996.

[4] F. El Aamrani, I. Casas, J. Pablo, L. Duro, M. Grive and J. Bruno, "Experimental and Modeling Study of the Interaction between Uranium (VI) and Magnetite," $S K B T e$ chnical Report, 1999.

[5] M. A. Glaus, B. Baeyens, M. Lauber, T. Rabung and L. R. Van Loon, "Water-Extractable Organic Matter from Opalinus Clay: Effect on Sorption and Speciation of Ni(II), Eu(III) and Th(IV)," Nagra Technical Report, 2001, pp. 1-7.

[6] N. Marmier, A. Delisee and F. Fromage, "Surface Complexation Modeling of $\mathrm{Yb}(\mathrm{III}), \mathrm{Ni}(\mathrm{II})$, and $\mathrm{Cs}(\mathrm{I})$ Sorption on Magnetite,"Journal of Colloid and Interface Science, Vol. 211, No. 1, 1999, pp. 54-60. doi:10.1006/jcis. 1998.5968

[7] A. Gustafsson, M. Molera and I. Puigdomenech, "Study of Ni(II) Sorption on Chlorite a Fracture Filling Mineral in Granites, in: Scientific Basis for Nuclear Waste Management XXVIII," Materials Research Society Symposium Proceedings, Vol. 824, 2004, pp. 373-378.

[8] S. Holgersson, "Oskarshamn Site Investigation. Batch Experiments of I, Cs, Sr, Ni, Eu, U and Np Sorption onto Soil from the Laxemar Area," SKB., 2009, pp. 9-29.

[9] R. E. Grim, "Clay Mineralogy," Second Edition, McGrawHill Book Co., New York, 1968.

[10] H. H. Murray, "Traditional and New Application for 
Kaolin, Smectite, and Palygorskite: A General Overview," Applied Clay Science, Vol. 17, No. 5-6, 2000, pp. 207-221. doi:10.1016/S0169-1317(00)00016-8

[11] H. Y. Jo, C. H. Benson and T. B. Edil, "Rate-Limited Cation Exchange in Thin Bentonitic Barrier Layers," Canadian Geotechnical Journal, Vol. 43, No. 4, 2006, pp. 370-391. doi:10.1139/t06-014

[12] J. Sampler, L. Zheng, L. Montenegre, A. M. Fernandez and P. Rivas, "Coupled Thermo-Hydro-Chemical Models of Compacted Bentonite after FEBEX in Situ Test," Applied Geochemistry, Vol. 23, No. 5, 2008, pp. 11861201. doi:10.1016/j.apgeochem.2007.11.010

[13] A. Harrane, M. A. Belaouedj and M. Belbachir, "Cationic Ring-Opening Polymerization of (d,1-Lactide) Using Maghnite- $\mathrm{H}^{+}$, a Non-Toxic Catalyst," Reactive and Functional Polymers, Vol. 71, No. 2, 2011, pp. 126-130. doi:10.1016/j.reactfunctpolym.2010.11.022

[14] C. E. Weaver and L. D. Pollard, "The Chemistry of Clay Minerals," Elsevier Science Publishing Company, Oxford, 1975, p. 212.

[15] S. S. Guptaa and K. G. Bhattacharyya, "Immobilization of $\mathrm{Pb}(\mathrm{II}), \mathrm{Cd}(\mathrm{II})$ and $\mathrm{Ni}(\mathrm{II})$ Ions on Kaolinite and Montmorillonite Surfaces from Aqueous Medium," Journal of Environmental Management, Vol. 87, No. 1, 2008, pp. 46-58. doi:10.1016/j.jenvman.2007.01.048

[16] N. Sarier and E. Onder, "Organic Modification of Montmorillonite with Low Molecular Weight Polyethylene Glycols and Its Use in Polyurethane Nanocomposite Foams," Thermochimica Acta, Vol. 510, No. 1-2, 2010, pp. 113-121. doi:10.1016/j.tca.2010.07.004

[17] N. Sarier, E. Onder and S. Ersoy, "The Modification of Na-Montmorillonite by Salts of Fatty Acids: An Easy Intercalation Process," Colloids and Surfaces A: Physicochemical and Engineering Aspects, Vol. 371, No. 1-3, 2010, pp. 40-49. doi:10.1016/j.colsurfa.2010.08.061

[18] J. D. Desai, H. M. Pathan, S. K. Min, K. D. Jung and O. S. Joo, "FT-IR, XPS and PEC Characterization of Spray Deposited Hematite Thin Films," Applied Surface Science, Vol. 252, No. 5, 2005, pp. 1870-1875. doi:10.1016/j.apsusc.2005.03.135

[19] A. Leszczynska, J. Njuguna, K. Pielichowski and J. R. Banerjee, "Polymer/Montmorillonite Nanocomposites with Improved Thermal Properties Part II. Thermal Stability of Montmorillonite Nanocomposites Based on Different Polymeric Matrixes," Thermochimica Acta, Vol. 454, No. 1, 2007, pp. 1-22.

[20] O. Abollino, M. Aceto, M. Malandrino, C. Sarzanini and E. Mentasti, "Adsorption of Heavy Metals on Na-Montmorillonite. Effect of pH and Organic Substances," Water Research, Vol. 37, No. 7, 2003, pp. 1619-1627. doi:10.1016/S0043-1354(02)00524-9
[21] S. S. Gupta and K. G. Bhattacharyya, "Immobilization of $\mathrm{Pb}(\mathrm{II}), \mathrm{Cd}(\mathrm{II})$ and $\mathrm{Ni}(\mathrm{II})$ Ions on Kaolinite and Montmorillonite Surfaces from Aqueous Medium," Journal of Environmental Management, Vol. 87, No. 1, 2008, pp. 46-58. doi:10.1016/j.jenvman.2007.01.048

[22] Q. H. Fan, D. D. Shao, J. Hu, W. S. Wu and X. K. Wang, "Comparison of $\mathrm{Ni}^{2+}$ Sorption to Bare and ACT-Graft Attapulgites: Effect of $\mathrm{pH}$, Temperature and Foreign Ions," Surface Science, Vol. 602, No. 3, 2008, pp. 778785. doi:10.1016/j.susc.2007.12.007

[23] X. K. Wang, C. L. Chen, W. P. Hu, A. P. Ding, D. Xu and X. Zhou, "Sorption of 243Am(III) to Multiwall Carbon Nanotubes," Environmental Science \& Technology, Vol. 39, No. 8, 2005, pp. 2856-2860. doi:10.1021/es048287d

[24] S.-C. Tsai, S. Ouyang and C.-N. Hsu, "Sorption and Diffusion Behavior of Cs and Sr on Jih-Hsing Bentonite," Applied Radiation and Isotopes, Vol. 54, No. 2, 2001, pp. 209-215. doi:10.1016/S0969-8043(00)00292-X

[25] K. G. Bhattacharyya and S. S. Gupta, "Kaolinite and Montmorillonite as Adsorbents for Fe(III), Co(II) and $\mathrm{Ni}(\mathrm{II})$ in Aqueous Medium," Applied Clay Science, Vol. 41, No. 1-2, 2008, pp. 1-9. doi:10.1016/j.clay.2007.09.005

[26] I. Langmuir, "The Adsorption of Gases on Plane Surfaces of Glass, Mica and Platinum," Journal of American Society, Vol. 40, No. 9, 1918, pp. 1361-1403. doi:10.1021/ja02242a004

[27] M. I. Kandah and J.-L. Meunier, "Removal of Nickel Ions from Water by Multi-Walled Carbon Nanotubes," Journal of Hazardous Materials, Vol. 146, No. 1-2, 2007, pp. 283-288. doi:10.1016/j.jhazmat.2006.12.019

[28] H. Freundlich, "Über die Adsorption in Lösungen," Zeitschrift für Physikalische Chemie (Leipzig), Vol. 57, 1906, pp. 385-470.

[29] R. Al Dwairi and A. Al-Rawajfeh, "Removal of Cobalt and Nickel from Wastewater by Using Jordan Low-Cost Zeolite and Bentonite," Journal of the University of Chemical Technology and Metallurgy, Vol. 41, No. 1, 2012, pp. 69-76.

[30] D. Xu, X. L. Tan, C. L. Chen and X. K. Wang, “Adsorption of $\mathrm{Pb}$ (II) from Aqueous Solution to MX-80 Bentonite: Effect of $\mathrm{pH}$, Ionic Strength, Foreign Ions and Temperature," Applied Clay Science, Vol. 41, No. 1-2, 2008, pp. 37-46. doi:10.1016/i.clay.2007.09.004

[31] E. Eren, "Removal of Copper Ions by Modified Unye Clay, Turkey," Journal of Hazardous Materials, Vol. 159, No. 2-3, 2008, pp. 235-244.

doi:10.1016/j.jhazmat.2008.02.035 